Max-Planck-Institut für demografische Forschung

Max Planck Institute for Demographic Research

Konrad-Zuse-Strasse 1 - D-18057 Rostock - GERMANY

Tel +49 (0) 3812081 - 0; Fax +49 (0) 3812081 - 202;

http://www.demogr.mpg.de

MPIDR WORKING PAPER WP 2012-012

FEBRUARY 2012

Family, Money, and Health:

Regional Differences

in the Determinants

of Life Cycle Life Satisfaction

Rachel Margolis (rachel.margolis@uwo.ca)

Mikko Myrskylä (myrskyla@demogr.mpg.de)

(C) Copyright is held by the authors.

Working papers of the Max Planck Institute for Demographic Research receive only limited review. Views or opinions expressed in working papers are attributable to the authors and do not necessarily reflect those of the Institute. 


\title{
Family, Money, and Health: \\ Regional Differences in the Determinants of Life Cycle Life Satisfaction
}

\author{
Rachel Margolis [1] \\ Mikko Myrskylä [2]
}

\begin{abstract}
We examine how family, money, and health explain variation in life satisfaction ("happiness") over the life cycle. Globally, these factors explain a substantial fraction of happiness, increasing from 12 percent in young adulthood to 15 percent in mature adulthood. Health is the most important factor, and its importance increases with age. Income is important only at ages below 50. Remarkably, the contribution of family is small across ages. Across regions health is most important in the wealthier, and income in the poorer regions of the world. Family explains a substantial fraction of happiness only in Western Europe and Anglophone countries.
\end{abstract}

Keywords: life satisfaction, life cycle, happiness, mental health, cross-national, aging

[1] Department of Sociology, University of Western Ontario, Social Sciences Center \#5326, London, Ontario N6A 5C2, Canada. Email: rachel.margolis@uwo.ca

[2] Max Planck Institute for Demographic Research, Konrad-Zuse-Str 1, 18057 Rostock, Germany. Email: myrskyla@demogr.mpg.de 


\section{Introduction}

Family, money and health are important determinants of life satisfaction. However, little is known about their relative importance at different stages of life, or how their importance varies across regions. In particular, nothing is known about how patterns of life cycle happiness may differ by region and why. This far, the literature has focused only on unraveling the average happiness trajectory over the life course. While some research has found happiness throughout the life cycle to be flat (Myers 2000), others have found that the old are happier than the young (Argyle 1999), still other research has found an upside down U-shape, with happiness peaking in midlife (Easterlin 2006). One reason for the discrepancies may be measurement — some studies estimate life course happiness from synthetic cohorts while others use panel data. However, even panel studies do not concur on the life cycle pattern of happiness (Easterlin 2006).

One useful conceptual framework for understanding the life cycle pattern of happiness is the life domain approach (Campbell 1981; Campbell, Converse and Rodgers, 1976). The life domain approach views responses on happiness as the net outcome of reported satisfaction with various domains of life that matter for happiness. Some of such factors are material living conditions, family life, health, and work. Proponents of the life domain approach to happiness argue that it captures both subjective and objective factors that affect happiness and classifies important aspects of everyday life that people refer to when answering about their overall happiness. While there is no complete agreement on what the most important factors are, virtually all researchers agree that economic conditions, family circumstances, health, and work are important domains determining happiness (Cummins 1996; Easterlin 2006; Salvatore and Munoz Sastre 2001; Saris et al. 1995; Van Praag and Ferrer-I-Carbonell 2004). A good example of the life domain approach to explaining life cycle happiness is Easterlin (2006), who studies happiness in the U.S. and finds an upside 
down U-shaped happiness curve over the life cycle. Easterlin concludes that the pattern is due to varying patterns of life satisfaction on each of the examined domains over the life cycle. For example, he finds that satisfaction with family life and work increase until midlife and then decrease, while satisfaction with financial situation increases with age, and satisfaction with health decreases with age.

We extend the research on life cycle happiness in several ways. Although prior research has analyzed the factors explaining the level of happiness (Easterlin 2006), no attempt has been made to analyze the factors responsible for the variation in the happiness. We first ask what factors explain variation in happiness at different stages of life, and how the importance of these factors changes over the life course. The factors that we examine are family (partnership and children), money, and health. We do not consider work separately as the mechanism through which work influences life satisfaction is to large extent captured by income. Further, we take a comparative approach and study regional variation in the importance of different life domains in explaining variation in life satisfaction over the life cycle. This is important because the factors that we consider may have very different meanings and importance for life satisfaction across regions. Consider, for example, health. First, we expect the importance of health in explaining happiness to vary across regions as the prevalence of poor health varies across reasons. Second, and more importantly, we expect the importance of being in poor versus good health on happiness to vary across regions, partly because of cultural differences in the acceptance of different health statuses, partly because of the variation in the ability of health systems to alleviate suffering given a health condition. Regions differ also in terms of variation in income and family formation as well as in the happiness differences associated with different income levels and family statuses. Thus for a more complete understanding of how family, money and health explain variation in happiness across the life cycle, the regional approach is very important. 


\section{Regional Variation in Happiness}

Several studies attempt to explain national and regional differences in levels of happiness based on economic conditions, cultural factors, and other contextual characteristics (Alesina, DiTella and MacCulloch 2004; Deaton 2008; Diener and Suh 2000; Frey and Stutzer 2002; Kalmijn 2009; Soons and Kalmijn 2009; Schyns 1998). However, no work to our knowledge has addressed regional variation in the relative importance of the determinants of life cycle happiness. When studying the relative importance of various factors in explaining variation in happiness over the life cycle, it is important to distinguish between the magnitude of the effect $^{1}$ of a given factor, and the population level explanatory power of that factor. We examine variation explained by each factor with the $\mathrm{R}^{2}$ and semi-partial correlation coefficient. These measures of variation depend essentially on two measures. The first is the variation in the factor of interest. The second is the difference in happiness between those in different categories. Assume, for example, that people can be either in good or poor health. Then the population level importance of health in determining variation in happiness depends on the proportion of the population in poor health (which is quadratically related to the variation in the variable of interest) and the average difference in happiness between people in the two health states (which we call the effect size; see footnote 1). Both of these factors are expected to vary with age. The demographer's perspective, thus, is useful in examining the importance of each factor by age at the population level.

We consider the interplay between effect size and variation of a given factor in explaining variation in happiness. We expect the relative importance of different life domains to vary across the life cycle and across regions. Consider first the life cycle differences. At younger ages family, income, and health might explain some proportion of the variance in happiness while few are married, well-off, and in poor health. At older ages the variation in

\footnotetext{
${ }^{1}$ The term "effect" here means the regression coefficient describing the happiness difference of persons in differing family situations, differing income groups, or differing health statuses. We do not put any causal interpretation on these regression coefficients.
} 
marital status and wealth increases, as does the prevalence of poor health. Simultaneously, the individual level importance of these factors on happiness may also change. These changes over the life course are expected to influence the relative importance of different life domains in explaining variation in happiness over the life course.

\section{Regional Differences in Life Domains}

We expect to find regional differences in the importance of different life domains in explaining variation in happiness over the life cycle. This is because the variation in the factors that we consider, and differences in well-being between groups are both likely to vary across regions. Consider, for example, health as the variable of interest, and denote $(p)$ as the prevalence of poor health, and $(b)$ as the effect on happiness of being in poor health. Regions differ in the prevalence of poor health $(p)$. Regions may also differ in the ability of health systems to alleviate suffering given a condition affecting the well-being of those in poor heath relative to those in good health. This would influence the effect size $(b)$. Combined, regional variation in prevalence and effect size may influence the explanatory power of health on happiness. The prevalence of poor health depends on age, as poor health is most common among older people. The individual level effect of poor health may also depend on age, though the direction of the age pattern is not a priori clear. Jointly, these factors may give rise to changing importance of health in explaining happiness over the life cycle.

Similarly, different levels of income inequality affect the proportion of people in various strata of society $(p)$. Moreover, the type of welfare state influences how income is redistributed which is expected to influence the magnitude of the happiness difference between the well off and the less-well off $(b)$. The importance of family factors might also vary by region. We conceptualize two aspects of family factors- partnership and children. There are large regional differences in the proportion of those in different marital status 
groups and also in the well-being of those in various unmarried categories relative to the married (Kalmijn 2009; Stack and Eshleman 1998). Similarly, regional differences in fertility schedules affect the proportion of those in different parity groups over age and there are contextual differences in the well-being of those with and without children by region and welfare regime (Margolis and Myrskylä 2011).

\section{Research Questions}

In this paper, we explore the following questions:

1) How much of the variation in life satisfaction can be explained by family circumstances (partnership and children), money, and health?

2) Do these core factors explain more of life satisfaction in some parts of the life cycle rather than others?

3) Are there regional differences in the importance of these life domains in explaining variation in life satisfaction over the life cycle?

Answering these questions adds to prior research in three main ways. First, we contribute by defining a focus which complements existing research on life cycle life satisfaction with its focus on explaining variation in life cycle happiness rather than the level of well-being (Easterlin 2006). Second, we take a comparative approach and explore to what extent family, money, and health explain variation in life cycle life satisfaction in different regions of the world. Lastly, we apply simple methods to describe the variation explained by each life domain, as the variation of any given factor and the individual level impact of that factor on life satisfaction vary across regions and life stage. 


\section{Data}

We use the World Values Survey (WVS) to examine the determinants of life satisfaction throughout the life course in different regions of the world. The WVS assesses the state of socio-cultural, moral, and political values through a series of questionnaires implemented with face-to-face interviews. We use these data because it is the largest international survey that includes questions on life satisfaction as well as other major life domains.

In this analysis, we use survey waves conducted between 1981 and 2008 for respondents aged 20 and above at the time of the interview. Of the 308,738 respondents ages 20 or above, we exclude 54,569 because questions about health or income were not asked for that country and year, and we exclude 46,153 respondents because of missing data on the variables in our analysis. Thus, our analytic sample is comprised of 208,016 respondents from 90 countries. We organize these countries into seven regions. The samples in developed countries are often close to representative, however samples from developing countries are not random (Inglehart et al. 2000). We discuss how the sampling strategy in developing countries affects our results at the end of the paper. We weight each country in the data set so that their weight in the final analyses are equal, no matter the number of waves conducted or sample size in each country. Thus, each individual's responses are weighted inversely to the number of respondents per country and countries with multiple surveys do not count more than those with only one survey.

\section{Dependent Variable}

The dependent variable is the respondent's reported level of life satisfaction. Respondents were asked, “All things considered, how satisfied are you with your life as a whole these days? Please use this card to help with your answer." Possible responses ranged from 1, "dissatisfied" to 10 "satisfied". We treat life satisfaction as a continuous variable with 
observed range from 1 to 10. Prior research has found that assumption of ordinality or cardinality of happiness and life satisfaction scores make little difference (Ferrer-i-Carbonell and Frijters 2004).

\section{Explanatory Variables}

To explore the age patterns of happiness and its determinants, we stratify our analysis by age. We use three age groups: 20-34, 35-49, and 50 and above, which correspond to young adults, middle-aged adults, and mature adults. Our four main explanatory variables are health, relative income, partnership status, and children. Health is the individuals' subjective state of health. Respondents were asked, "All in all, how would you describe your state of health these days? Would you say it is: very good, good, fair, poor, or very poor?" We code responses as a continuous variable in order to maximize the degree of variation explained by health.

We measure income relative to the context in which one lives, which has shown to be a more important predictor of happiness than an absolute measure of income (Easterlin 1995). Respondents were shown a card representing a scale of incomes ranging from 1 "lowest income decile" to 10, the "highest income decile". Respondents were asked in which group their household was, "including all wages, salaries, pensions and other incomes that come in." We code relative income as a continuous variable.

We examine two aspects of family — partnership status and children, both of which have been found to be associated with happiness (Kalmijn 2009; Margolis and Myrskylä 2011; Soons and Kalmijn 2009; Stack and Eshleman 1998). Partnership status is measured as either partnered (married or living together as married), or un-partnered (separated, divorced, widowed, single). We measure number of children as: none, one, two, or three or more.

To examine variation by region in the relative importance of the above factors to 
happiness, we examine eight world regions. Our categories are: Western Europe, Eastern Europe (Former Socialist States), Anglophone countries, Middle East and North Africa, SubSaharan Africa, Latin America, and Asia.

\section{Empirical Approach}

First we present the total percentage of the variation in life satisfaction at different phases of the life course explained by each of these factors combined. For each age group and region, we regress health, income, family (partnership and children), and a dummy variable for gender on life satisfaction. Equation (1) presents a linear regression model with life satisfaction as the dependent variable $(y)$ and health $(\mathrm{H})$, income $(\mathrm{I})$, partnership $(\mathrm{P})$, children $(\mathrm{C})$, and gender $(\mathrm{G})$ as independent variables:

$$
y=\beta_{0}+\beta_{1} \mathrm{H}+\beta_{2} \mathrm{I}+\beta_{3} \mathrm{P}+\beta_{4} \mathrm{C}+\beta_{5} \mathrm{G}+\mathrm{e}
$$

We graph the $\mathrm{R}^{2}$ for this regression for each age group and region in our analysis. All of the analysis is weighted, such that each region is equally comprised of respondents from each country. Next, we examine the relative contribution of each of these factors to explaining variation in life satisfaction, net of the other examined factors. We calculate the semi-partial correlation coefficient for each of these factors, which represents the proportion of the variation in life satisfaction explained by each factor, net of the other examined factors, and a combined factor. The combined factor is the proportion of the variation jointly explained by the intersection of the examined factors. We chart the semi-partial correlation coefficients by age and region to examine the relative contribution of each factor to variation in life satisfaction.

In the Appendices, we present summary measures of the statistical relationships between each life domain factor and life satisfaction. We graph the $\mathrm{R}^{2}$, or percentage of 
variation explained by each factor in total with measures of $(b)$ the difference in life satisfaction between the groups, and $(p)$ the prevalence or variation in each factor.

To test the robustness of our results, we do several sensitivity checks. First, we replicate our analysis including country fixed effects, in order to control for country level differences in the levels of reported happiness. As expected, the analysis with country fixed effects explains a slightly greater proportion of the variation in life satisfaction for all regions, however we see the same patterns for the family, health and money variables as presented in this paper. Therefore, we exclude these results for simplicity. Second, we conducted our analysis using alternate coding schemes for health, income, and children. We analyzed health coding in various ways (dichotomous, relative health per age group, and relative health per age and country) and found similar results and therefore chose the simplest coding. We conducted our analysis coding household income differently, for example with income quantiles and tertiles, but found similar results. Therefore in this manuscript we choose the simplest coding scheme. The results were also similar when coding children with different categories. We also conducted our analysis with different categories of countries and found a similar pattern of results. For example, we examined the results when analyzing more and less developed East Asian countries separately and found. Lastly, we find the same pattern of results when we examine variation in happiness (measured with the question, "Taken all things together, would you say you are very happy, quite happy, somewhat happy, or not at all happy?), rather than life satisfaction. We use life satisfaction in the analysis because it is measured on a ten point scale, rather than a four point scale, and therefore captures more variation. Last, we ran our analysis separately for men and women and found similar patterns of results. 


\section{Results}

Table 1 presents the 90 countries in the analytic sample by region. We examine seven regions in this paper: Western Europe, Eastern Europe, Anglophone countries, Middle East and North Africa, Sub-Saharan Africa, Latin America, and Asia. Although there is certainly variation within these country groups, in this paper we examine variation between these large regions. Stratifying the analysis further would not be feasible because of diminishing sample size.

In our first set of results, we examine the relative importance of family, money, and health across regions. Figure 1 presents the proportion of variation in life satisfaction explained by each of these three life domains. ${ }^{2}$ Health is the most important and it matters for explaining life satisfaction in all regions. It explains between four and nine percent of variation in life satisfaction for the regions shown, net of other factors. It matters most in Western Europe, but is important in all regions.

Income is also important for explaining variation in life satisfaction, but is most important in poor regions and is least important in regions with high GDP/capita. Household resources explain less than one percent of variation in life satisfaction in Western Europe and Anglophone countries, but six to seven percent in Asia and Sub-Saharan Africa. It may be that the welfare state guarantees a lower bound on income and a level of basic needs in the richest regions and that income is most important for life satisfaction in areas where absolute poverty is most common.

Family explains a small amount of variation in life satisfaction in Western Europe and Anglophone countries, and a negligible amount in other regions. Globally, children matter next to nothing for explaining variation in life satisfaction (results not shown). In Western Europe and Anglophone countries the explanatory power is attributable to partnership, not children (results not shown separately for these two family variables). In particular, the small

\footnotetext{
${ }^{2}$ This figure charted with $\mathrm{R}^{2}$ has the same pattern.
} 
amount of variation that is explained by family is due to large differences in the beta, in the well-being of those partnered compared to those un-partnered, and the most variation in marital status in these regions.

Figure 1 highlights different patterns in the relative importance of the three life domains for the regions in our analysis. In the two most developed regions, Western Europe and Anglophone countries, health is the most important factor, with family a far second, and income explaining hardly any variation in life satisfaction. In Latin America, health is also the dominant factor. However here, as in all regions other than Western Europe and Anglophone countries, income explains more of the variation than family. Eastern Europe has the median pattern, with health the most important, followed by income which explains about half as much variation as health, and family mattering hardly at all. The last three regions, the Middle East and North Africa, Asia, and Sub-Saharan Africa, are the regions with the lowest GDP/capita. Income and health both matter a lot in these regions. The only two regions in which income matters more than health are the poorest regions Asia and SubSaharan Africa.

Next, we examine whether family, money, and health are more important for explaining variation in life satisfaction in some periods of the life course than others. Figure 2 charts the proportion of life satisfaction explained by each of the life domains and their total for the global sample by age group. The total for all life domains is the $\mathrm{R}^{2}$ and the variation explained by each factor is the semi-partial correlation coefficient for each of these factors, which represents the proportion of the variation in life satisfaction explained by each factor, net of the other examined factors, and a combined factor. Family, money, and health together explain a substantial amount of variation in life satisfaction, 12 percent in young adulthood, 15 percent in middle adulthood, and 14 percent in mature adulthood. The increase in variation explained in the middle years is due to an increase in the importance of health and income 
for life satisfaction. In mature adulthood, health becomes even more important, yet income declines in importance, relative to younger ages. ${ }^{3}$

In Figure 3, we turn to regional variation in life satisfaction explained by family, money, and health jointly, across the life course. This figure charts the total proportion of the variation in life satisfaction explained by family, money, and health at each period of the life course for the regions of our analysis. We find that these factors explain the most in SubSaharan Africa. The life domains explain around ten percent of variation in young adulthood and slightly more in middle and mature adulthood for Asia, Eastern Europe, and Western Europe, and slightly less over age for Anglophone countries, Middle East, and Latin America.

To understand why these three life domains explain more variation in life satisfaction over the life course in Sub-Saharan Africa and approximately the same amount over the life course in other regions, we turn to Figures 4 to 6 which examine this for each life domain. These figures chart the proportion of variation explained by each life domain by region and age group. We chart the $\mathrm{R}^{2}$ in these tables rather than the semi-partial correlation coefficient ${ }^{4}$, because we want to examine the importance of health overall. The semi-partial correlation coefficient shows a more flat pattern over age, because it omits the variation explained by the combination, or overlap, of other factors with the target variable. At older ages, health becomes more correlated with the other factors we measure - income and family. The equivalent of Figures 4 to 6 calculated with the semi-partial correlation coefficient are found in Appendix Tables A1 to A3.

\footnotetext{
${ }^{3}$ Our global sampled is weighted such that each respondent has a weight proportional to the number of respondents from that country, with every country weighted as 1 . This scheme weights countries equally. We estimated an alternate weighting system which takes the means of regions, so as not to be influenced by the number of countries in each region and we find the same overall pattern, but a less sharp increase in the importance of health over age and a sharper decrease for income over age.

${ }^{4}$ The semi-partial correlation coefficient measures the relative contribution of each of these factors to explaining variation in life satisfaction, net of the other examined factors.
} 
Figure 4 shows that health explains increasingly more variation in life satisfaction over the life course for four of the seven regions - Western Europe, Sub-Saharan Africa, Eastern Europe, and Asia. These are the regions with the highest and lowest life expectancy. To examine whether the increase in variation explained by health over age is due to differences in well-being between those in good and poor health $(b)$ or the prevalence of poor health (p), we turn to Figures A4 and A5, which chart $(b)$ and $(p)$. The variation explained by health $\left(\mathrm{R}^{2}\right)$ is much more correlated with $(b)$ than $(p)^{5}$, which leads us to conclude that the increase in variation explained over age is due to increases in the relative well-being of those in good versus poor health $(b)$. The proportion of respondents in poor health increases over age for all regions (Table A1). In the Middle East/North Africa, Latin America, and Anglophone countries, health does not explain more variation in well-being over age. In these regions, the differences in life satisfaction between those in good and poor health are smaller (betas are flat over age). We conclude that beta, or the differences in life satisfaction for those at different levels of health, is the driving factor of this age pattern because the other contributing factor, the regions show similar increases in percentage of the population in poor health over age (Table A1).

Next, we examine the variation explained by income over the life course for the seven regions. Figure 5 shows that income explains very little variation in life satisfaction in Western Europe, Anglophone countries, and Latin America. In these regions, the differences in life satisfaction by income are small. However, income explains much more variation in the other regions. It explains the most in Sub-Saharan Africa, where differences in life satisfaction between those in good and poor health are largest. Moreover, income explains between four and eight percent of variation in life satisfaction in Asia, Middle East/North

\footnotetext{
${ }^{5} \mathrm{We}$ can use correlation between $\mathrm{R}^{2}$ and prevalence $\mathrm{p}$ to study whether the variation in $\mathrm{R}^{2}$ is attributable to prevalence even though the association between prevalence and variance is quadratic (increasing up to prevalence 0.5 , then decreasing). This is because the observed prevalence levels are mostly between 0 and 0.5 , the region in which increasing prevalence increases variance.
} 
Africa, and Eastern Europe. For these regions, income has the most importance in middle adulthood, when respondents are raising children and perhaps caring for the older generation as well. Appendix Figure A6 shows that the variation explained by income is almost linearly correlated with the differences in well-being between those with different incomes. This is expected since income is defined with respect to one's peers, and the variation in income is approximately the same across all regions and ages.

Figure 6 charts the variation explained by family over the life course. Surprisingly, family explains little variation, and the least of the three examined factors. Partnership and children combined explain almost no variation in life satisfaction for most regions. However, it explains between 2 and 5 percent of variation in life satisfaction for Western Europe and Anglophone countries. Why does family only explain some of the variation in life satisfaction in these regions and in young and middle adulthood, but not the other regions? As shown in Table A1, Western European and Anglophone countries have similar proportions partnered to other regions in the analysis, but much larger differences in well-being between those partnered and un-partnered. ${ }^{6}$ This may be due to higher levels of uncertainty about partnering during singlehood or it may be due to a higher rate of dissolution of bad partnerships leading to larger differences between those remaining partnered and those un-partnered.

\section{Discussion}

In this analysis, we extend prior research on life cycle happiness by taking a life domain approach to examining the relative importance of family, money, and health in determining variation in life cycle life satisfaction. The question is new, as is the method. We examine whether the importance of the life domains varies by region and age group is due to variation in a factor or the magnitude of the association between happiness and the factor. We use this

\footnotetext{
${ }^{6}$ Figures A7 and A8 also show that the little variance that is explained is mostly attributable to happiness differences between partnered and not partnered, rather than differences in the prevalence of partnered. This was the case also with health - the effect size, rather than variation, was more important.
} 
method to explore regional differences in the age pattern of happiness and its determinants. The three domains that we examine are health, income, and family (partnership and children). Globally, these factors together explain a substantial amount of variation, and an increasing amount over age - between 12 and 15 percent of variation in happiness.

Additionally, we studied regional variation in the importance of different life domains in explaining variation in happiness over the life cycle. Health matters most for happiness of these factors, and it matters more as age increases for most regions. Health is most important for Sub-Saharan Africa, where health is the worst of any region. Income matters about half as much as health, in explaining variation in happiness. Partnership explains much less than health and income, and only in Anglophone countries and Western Europe in young and middle adulthood. Number of children explains next to nothing compared to these other variables.

Breaking down the variation explained by each factor to that due to differences in life satisfaction by that dimension $(b)$ and the prevalence in each factor $(p)$ showed that $(b)$ was much more important for explaining variation in life cycle life satisfaction. Health was most important for life satisfaction in countries with the best and worst (Sub-Saharan Africa, Anglophone, and Western European countries) because these places have the largest differences in life satisfaction between those in good and poor health. Similarly, $(b)$ was also important for income. Resources were most important in explaining variation in life satisfaction in Sub-Saharan Africa and Asia, the regions where differences in life satisfaction between those with high and low resources were greatest. Lastly, partnership was most important for explaining life satisfaction in Western Europe and Anglophone countries, the regions where differences between those partnered and un-partnered are greatest.

In summary, our analysis shows that family, money and health are important factors explaining variation in happiness across the life course. However, there are large differences 
in the importance of these factors across the life course and across regions. The majority of the differences in the explanatory power of family, money and health over the life cycle and across regions is attributable to the individual-level happiness differences between people of different statuses rather than differences in variation. Prior research has found that satisfaction with health decreases at older ages, while satisfaction with financial situation increases with age (Easterlin 2006). Our results contribute to these findings in an important way. First, as satisfaction with financial situation increases with age, income also becomes a more important determinant of the variation in happiness. However, the importance of health in explaining population level variation in happiness also increases with age, despite people on average becoming less and less satisfied with their health status. These contrasts illustrate the usefulness of the population-level approach put forward in this paper which focuses on explaining variance, rather than on the magnitude of the coefficients. The latter approach, while useful for different kind of questions, could not inform us about whether certain factors are becoming more or less important in explaining population-level variation in life satisfaction.

This analysis has several limitations. First, the data available during our lifetimes do not allow us to examine happiness throughout the life course for many cohorts as they age. Therefore, we base our analysis on a synthetic cohort from successive cross-sections, analyzing the determinants of happiness for different age groups. The weakness of this method is that we are comparing persons of different birth cohorts with different life histories and do not know how different successive cohorts will be until they age. A second limitation of our analysis is that we deal with only three life domains: family, money, and health. We chose these because they have been well-studied and are thought to contribute to differences in well-being. However, future work can explore other domains such as work. Also, we focus 
on regional differences, rather than country-level differences. However, these can be explored in future work.

Despite limitations, this paper adds to the literature on life cycle in several important ways. First, while much literature has addressed the importance of economic and cultural factors in explaining regional and national differences in the levels of happiness (Cummins 1996; Easterlin 2006; Salvatore and Munoz Sastre 2001; Saris et al. 1995; Van Praag and Ferrer-I-Carbonell 2004), none has addressed the importance of life domains in explaining variation in happiness. Our method of breaking down variation into the prevalence $(p)$ and difference in well-being between factor groups $(b)$ provides a way to examine what drives the importance of a factor at a given age. Future work can extend this approach to explain national differences in variation in happiness or life satisfaction. Last, the importance of health found in this paper exemplifies another link between demographic behavior and selfreported well-being.

\section{Acknowledgements}

We gratefully acknowledge the helpful comments provided by Hans-Peter Kohler, Jason Schnittker, and Sam Preston. This research is supported by the National Institutes of HealthNational Institute on Aging (T32-AG000177 and P30 AG12836), the National Institute of Child Health and Human Development (T32 HD007242 and R24 HD 044964) at the University of Pennsylvania. 


\section{References}

Alesina, A., R. DiTella, and R. MacCulloch. (2004). Inequality and Happiness: Are Europeans and Americans different? Journal of Public Economics 88:2009-2042.

Argyle, M. (1999). Causes and Correlates of Happiness. In D. Kahneman, E. Diener, and N. Schwarz (Eds.), Well-being: The foundations of hedonic psychology (pp. 353-373). New York Russell Sage.

Campbell, A. (1981). The sense of well-being in America. New York: McGraw-Hill.

Campbell, A., P.E. Converse, and W.L. Rodgers. (1976). The quality of American life. New York: Russell Sage Foundation.

Cummins, R.A. (1996). The domains of life satisfaction: An attempt to order chaos. Social Indicators Research 38:303-328.

Deaton, A. (2008). Income, Aging, Health, and Well-being Around the World: Evidence from the Gallup World Poll. NBER Working Paper No. W13317.

Diener E. and E.M. Suh (Eds.) (2000). Culture and Subjective well-being. Cambridge, Mass: MIT Press.

Easterlin, R.A. (2006). Life cycle happiness and its sources: Intersections of psychology, economics, and demography. Journal of Economic Psychology. 27:463-482.

Easterlin, R.A. (1995). "Will Raising the Incomes of All Increase the Happiness of All." Journal of Economic Behavior and Organization 27(1):35-47.

Frey, B.S. and A. Stutzer. (2002). What Can Economists Learn from Happiness Research? Journal of Economic Literature 40(2):402-435.

Inglehart, R., C. Aguir, A. Ahmad, A. Aliev, R. Alishauskiene, and V. Andreyenkov. (2000). "World Values Surveys and European Values Surveys, 1981-84, 1990-93, and 1995-97 [Computer file]. ICPSR version." Ann Arbor, MI: Institute for Social Research.

Kalmijn, M. (2009). Country Differences in the Effects of Divorce on Well-being: The Role of Norms, Support, and Selectivity. European Sociological Review:1-16.

Margolis, Rachel, and Mikko Myrskylä. (2011). A Global Perspective on Happiness and Fertility. Population and Development Review 37(1): 29-56.

Myers, D.G. (2000). The Funds, Friends, and Faith of Happy People. American Psychologist 55(1):56-67.

Salvatore, N. and M.T. Munoz Sastre. (2001). Appraisal of life: "Area" version "Dimension" conceptualizations. Social Indicators Research 52:229-255.

Saris, W.E., R. Veenhoven, A.C. Scherpenzeel, and B. Bunting (Eds.) (1995). A comparative study of satisfaction with life in Europe. Budapest: Eotvos University Press. 
Schyns, P. (1998). Cross-national Differences in Happiness: Economic and Cultural Factors Explored. Social Indicators Research 43:3-26.

Soons, J.P.M., and M. Kalmijn. (2009). Is Marriage More than Cohabitation? Well-being Differences in 30 European Countries. Journal of Marriage and Family 71:1141-1157.

Stack, S. and J.R. Eshleman. (1998). Marital Status and Happiness: A 17-Nation Study. Journal of Marriage and Family 60(2): 527-536.

Van Praag, B.M.S., P. Frijters, and A. Ferrer-I-Carbonell. (2003). The anatomy of subjective wellbeing. Journal of Economic Behavior and Organization 51:29-49. 


\section{Tables and Figures}

Table 1. Countries in the Analytic Sample by Region, World Values Surveys (1981-2008)

\begin{tabular}{|c|c|c|c|c|c|c|}
\hline $\begin{array}{l}\text { Western } \\
\text { Europe }\end{array}$ & $\begin{array}{l}\text { Eastern } \\
\text { Europe }\end{array}$ & Anglophone & $\begin{array}{l}\text { Middle } \\
\text { East/North } \\
\text { Africa }\end{array}$ & $\begin{array}{l}\text { Sub-Saharan } \\
\text { Africa }\end{array}$ & $\begin{array}{l}\text { Latin } \\
\text { America }\end{array}$ & Asia \\
\hline Andorra & Albania & Australia & Algeria & Burkina Faso & Argentina & Bangladesh \\
\hline Austria & Azerbaijan & Canada & Egypt & Ethiopia & Brazil & China \\
\hline Belgium & Armenia & Gr. Britain & Iran & Ghana & Chile & India \\
\hline Cyprus & Bulgaria & Ireland & Iraq & Mali & Colombia & Indonesia \\
\hline Denmark & Belarus & USA & Jordan & Nigeria & $\begin{array}{l}\text { Dominican } \\
\text { Repub. }\end{array}$ & Japan \\
\hline Finland & Bosnian Fed. & & Morocco & Rwanda & El Salvador & Malaysia \\
\hline France & Serbia & & Saudi Arabia & South Africa & Mexico & Pakistan \\
\hline Germany & Croatia & & Turkey & Tanzania & Peru & Philippines \\
\hline Iceland & Czech Repub. & & & Uganda & Puerto Rico & S. Korea \\
\hline Italy & East Germany & & & Zambia & $\begin{array}{l}\text { Trinidad \& } \\
\text { Tobago }\end{array}$ & Taiwan \\
\hline Malta & Estonia & & & Zimbabwe & Uruguay & Thailand \\
\hline Netherlands & Georgia & & & & Venezuela & Vietnam \\
\hline Norway & Hungary & & & & & \\
\hline Portugal & Kyrgyzstan & & & & & \\
\hline Spain & Latvia & & & & & \\
\hline Sweden & Lithuania & & & & & \\
\hline \multirow[t]{10}{*}{ Switzerland } & Macedonia & & & & & \\
\hline & Moldova & & & & & \\
\hline & Poland & & & & & \\
\hline & Romania & & & & & \\
\hline & Russia & & & & & \\
\hline & Serbia \& & & & & & \\
\hline & Montenegro & & & & & \\
\hline & Slovakia & & & & & \\
\hline & Slovenia & & & & & \\
\hline & Ukraine & & & & & \\
\hline
\end{tabular}


Figure 1. Proportion of Variation in Life Satisfaction Explained by each Life Domain, Net of the Others, by Region

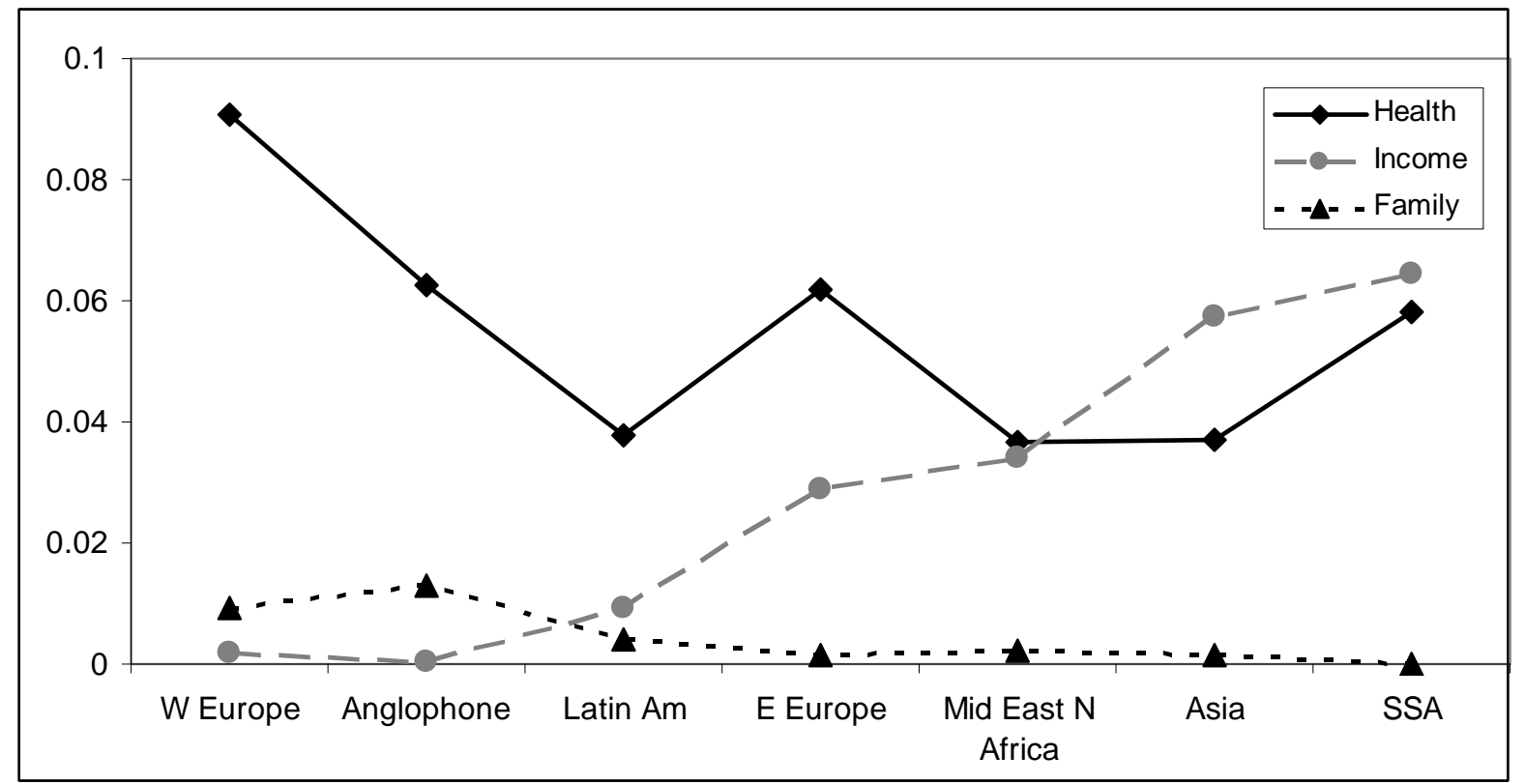

Notes:

Charts semi-partial correlation coefficient calculated also controlling for sex. Family is sum of partnership status and number of children. All ages combined.

Figure 2: Proportion of Variation in Life Satisfaction Explained by all Life Domains Together, and each Net of the Others, for the Global Sample by Age Group.

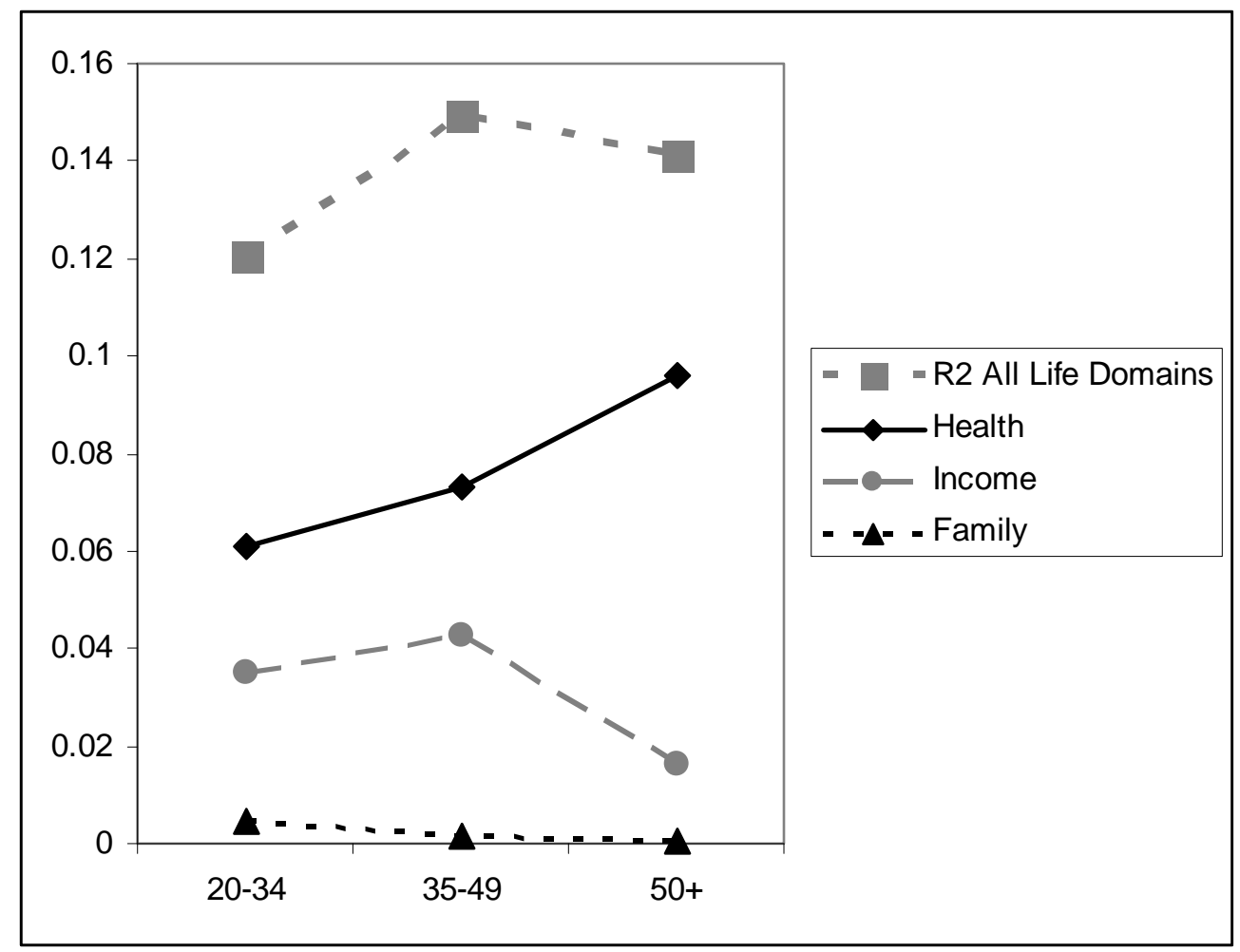

Notes:

Global sample is weighted such that each country weighted equally. 
Figure 3. Total Variation of Life Satisfaction Explained by Family, Money, and Health, by Region and Age Group

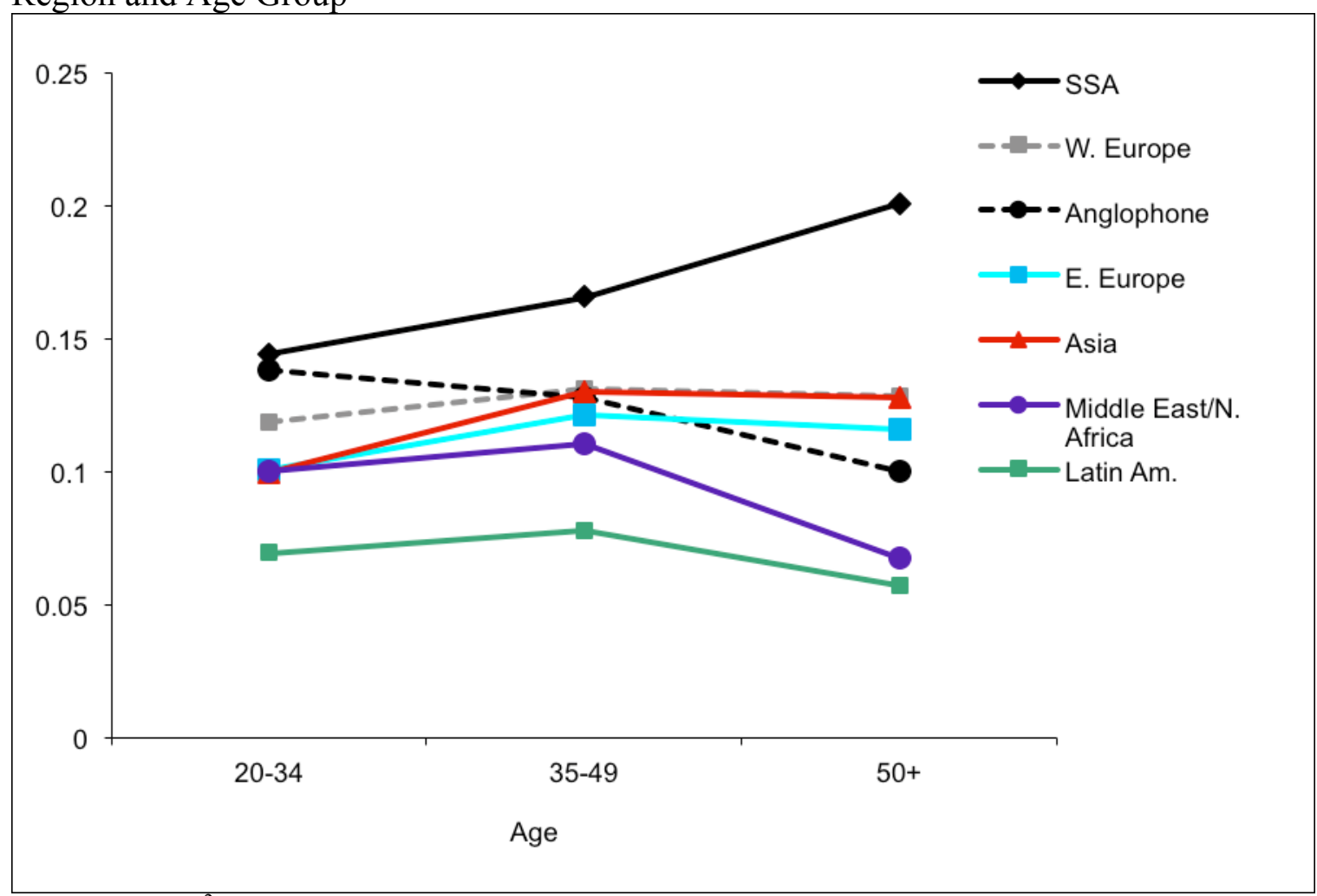

Notes: Charts $\mathrm{R}^{2}$ calculated from regressions by age group and region.

Figure 4. Proportion of Variation Explained by Health, by Region and Age Group

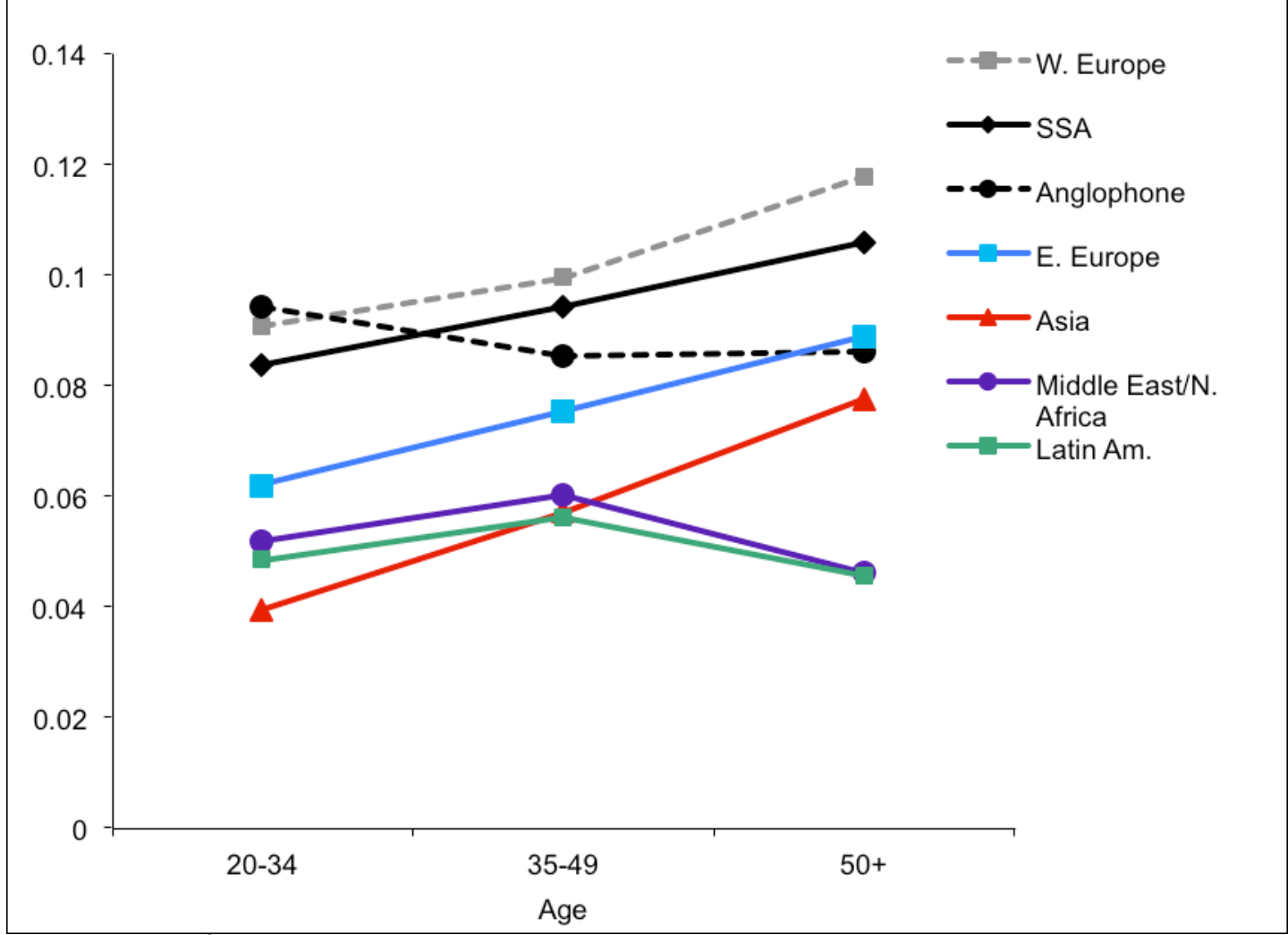

Notes: Charts $\mathrm{R}^{2}$ calculated from regressions by age group and region. Similar figure calculated with semi-partial correlation coefficient is available in Appendix Figure A1. 
Figure 5. Proportion of Variation Explained by Income, by Region and Age Group

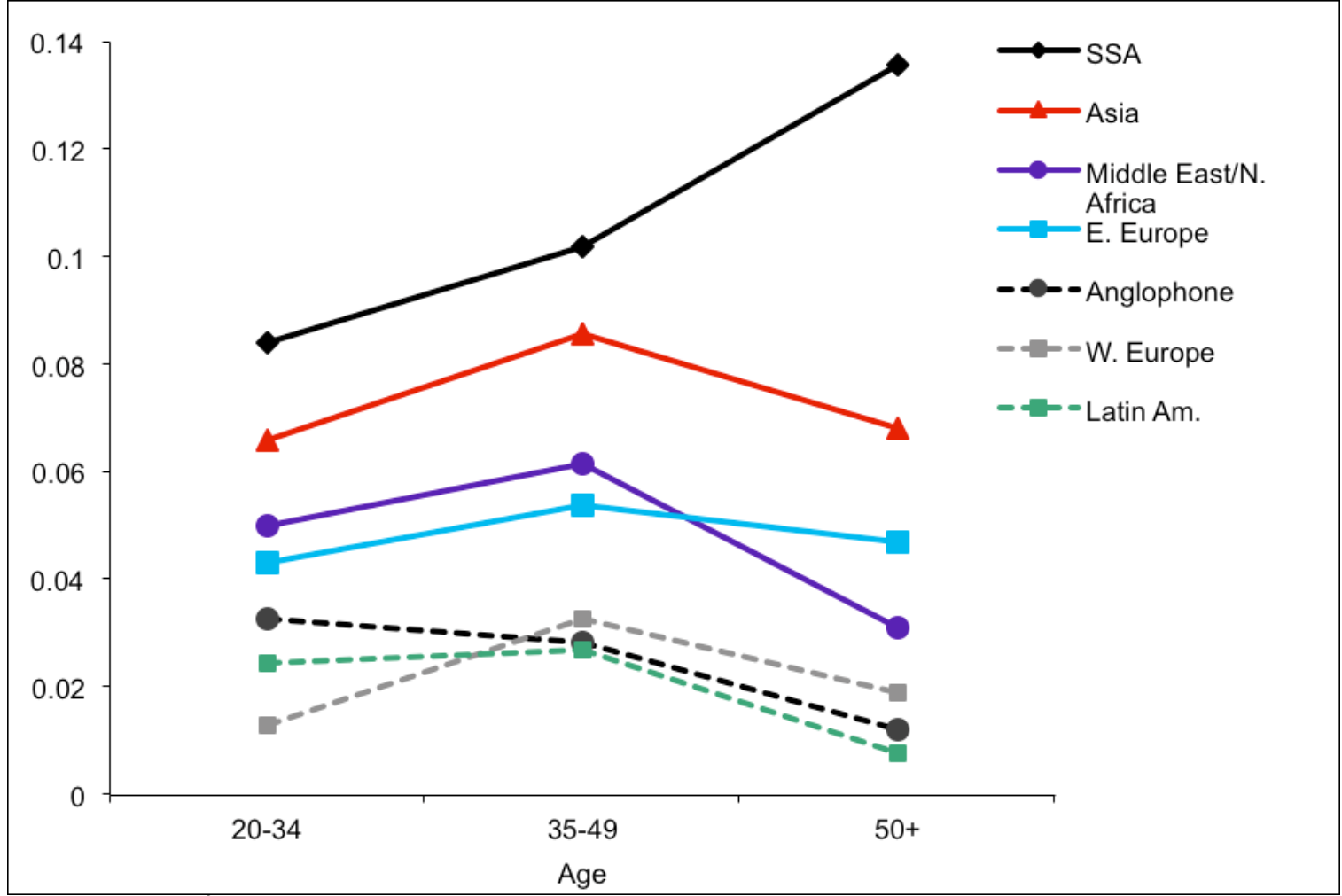

Notes: Charts $\mathrm{R}^{2}$ calculated from regressions by age group and region. Similar figure calculated with semi-partial correlation coefficient is available in Appendix Figure A2.

Figure 6. Proportion of Variation Explained by Family, by Region and Age Group

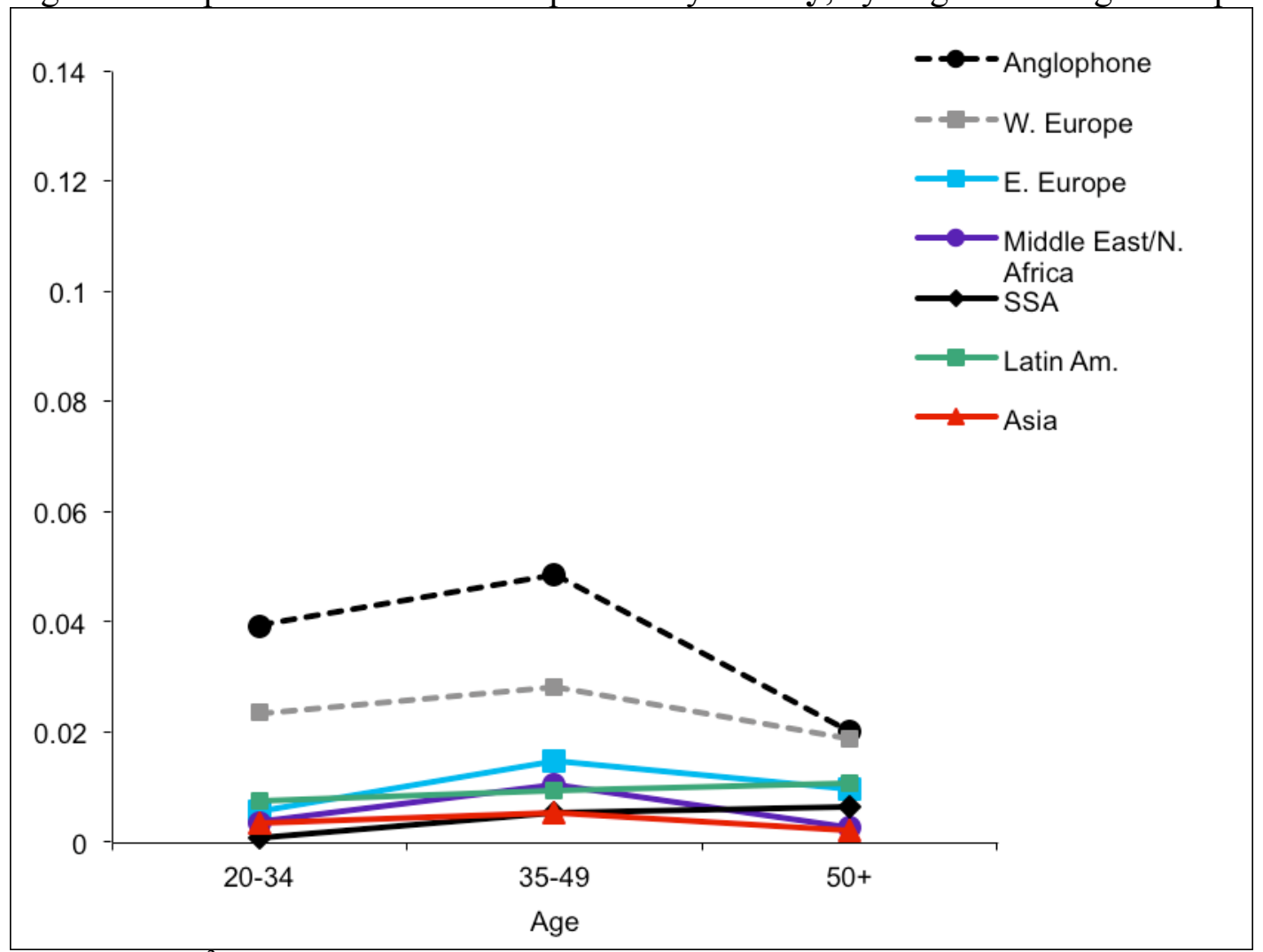

Notes: Charts $\mathrm{R}^{2}$ calculated from regressions by age group and region. Similar figure calculated with semi-partial correlation coefficient is available in Appendix Figure A3. 


\section{Appendices}

Figure A1. Proportion of Variation Explained by Health Net of other Factors, by Region and Age Group

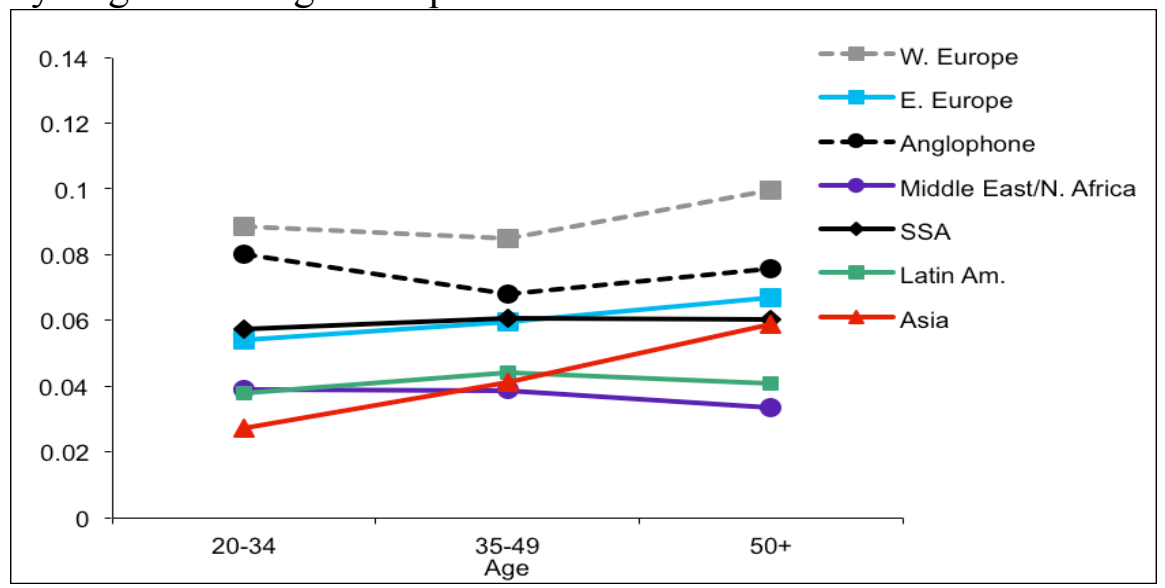

Notes: Charts semi-partial correlation coefficient.

Figure A2. Proportion of Variation Explained by Income Net of other Factors, by Region and Age Group

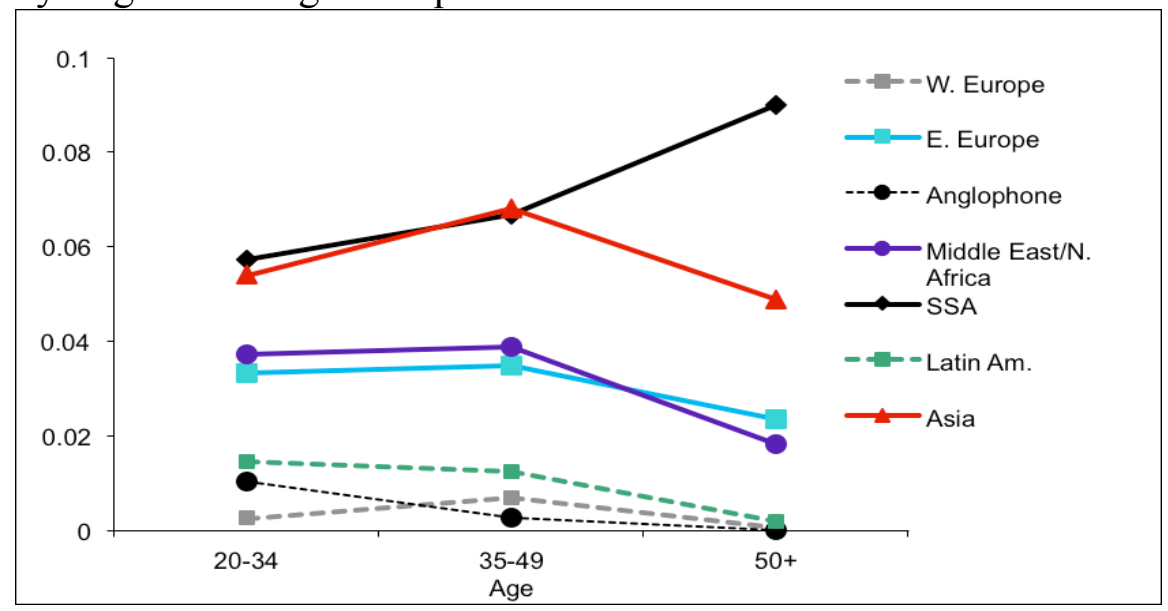

Notes: Charts semi-partial correlation coefficient.

Figure A3. Proportion of Variation Explained by Family Net of other Factors, by Region and Age Group

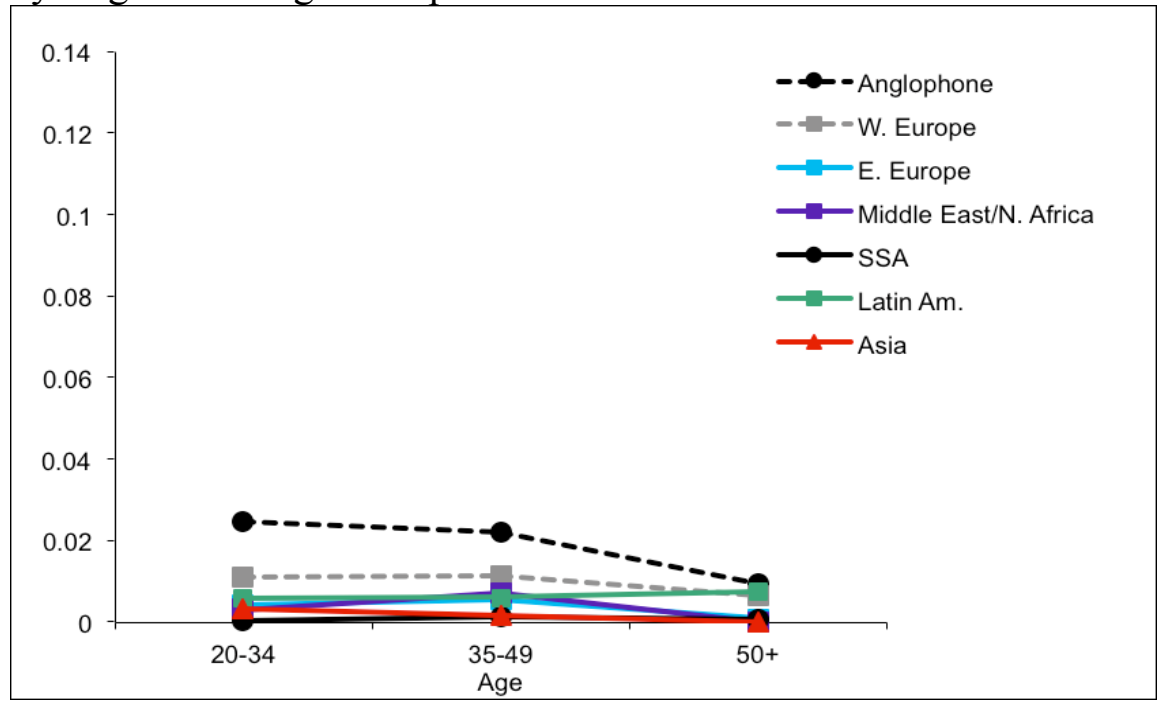

Notes: Charts semi-partial correlation coefficient. 
Figure A4. Measures of Variation Explained (R2) and Effect Size of Health

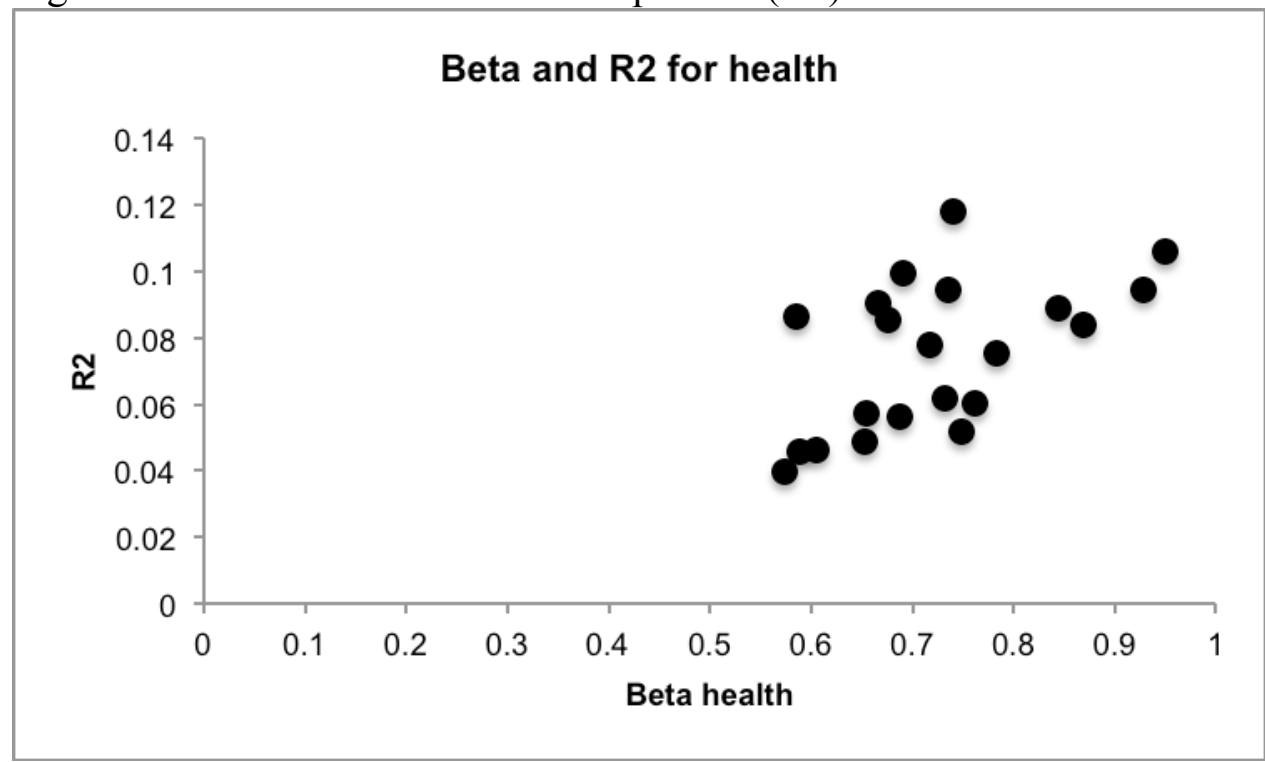

Figure A5. Measures of Variation Explained (R2) and Proportion in Poor Health

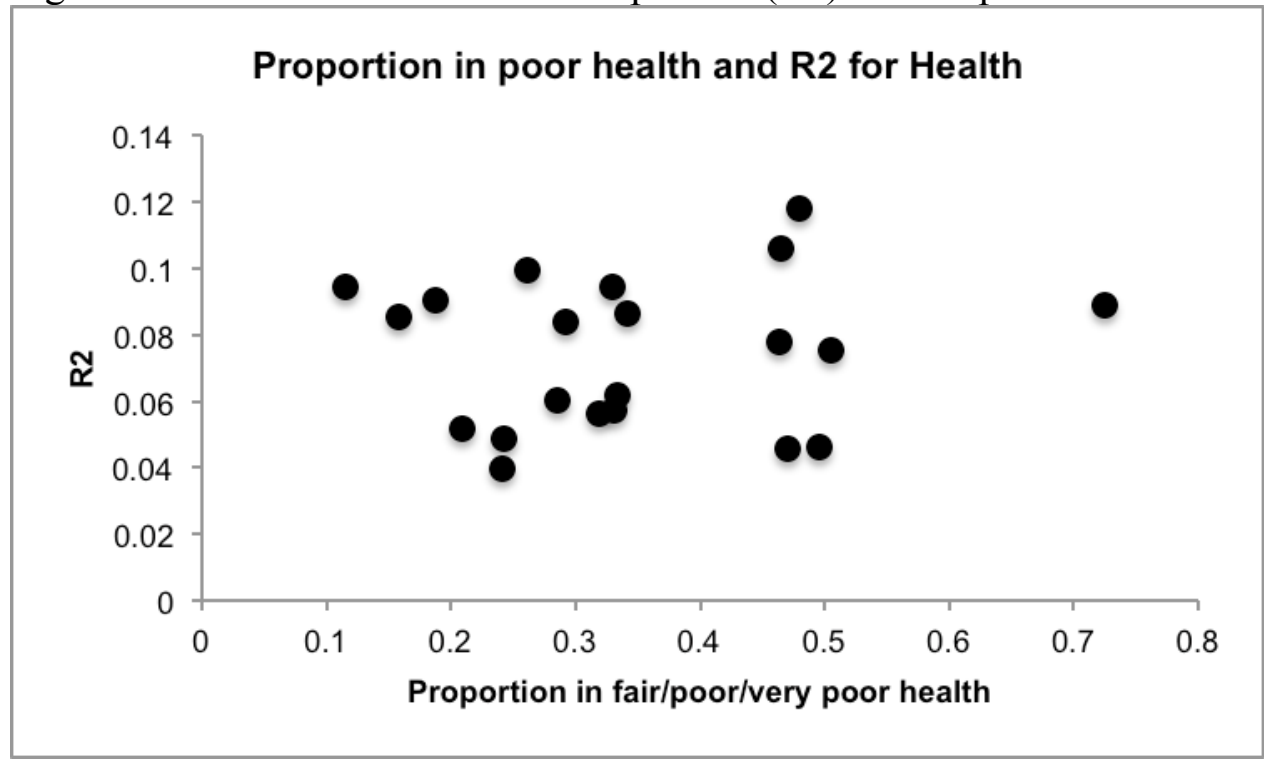


Figure A6. Measures of Variation Explained (R2) and Effect Size of Income

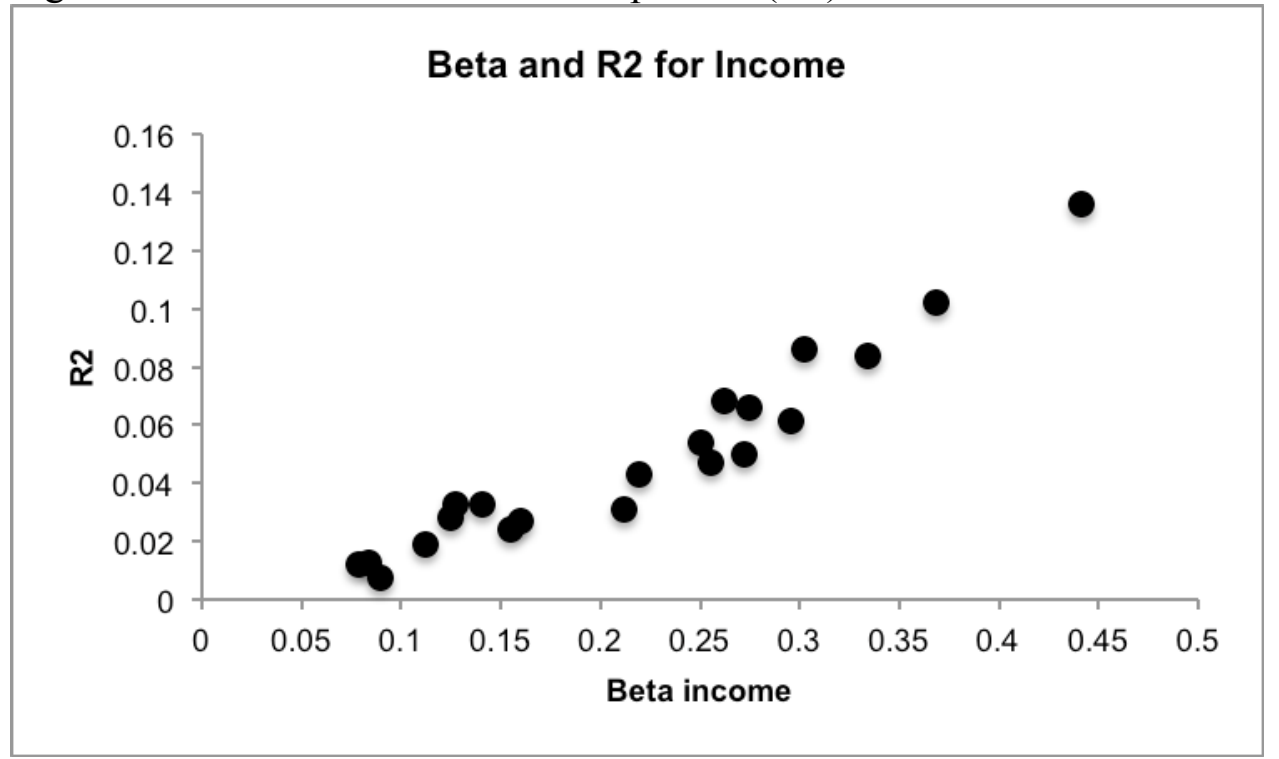


Figure A7. Measures of Variation Explained (R2) and Effect Size of Partnership Status

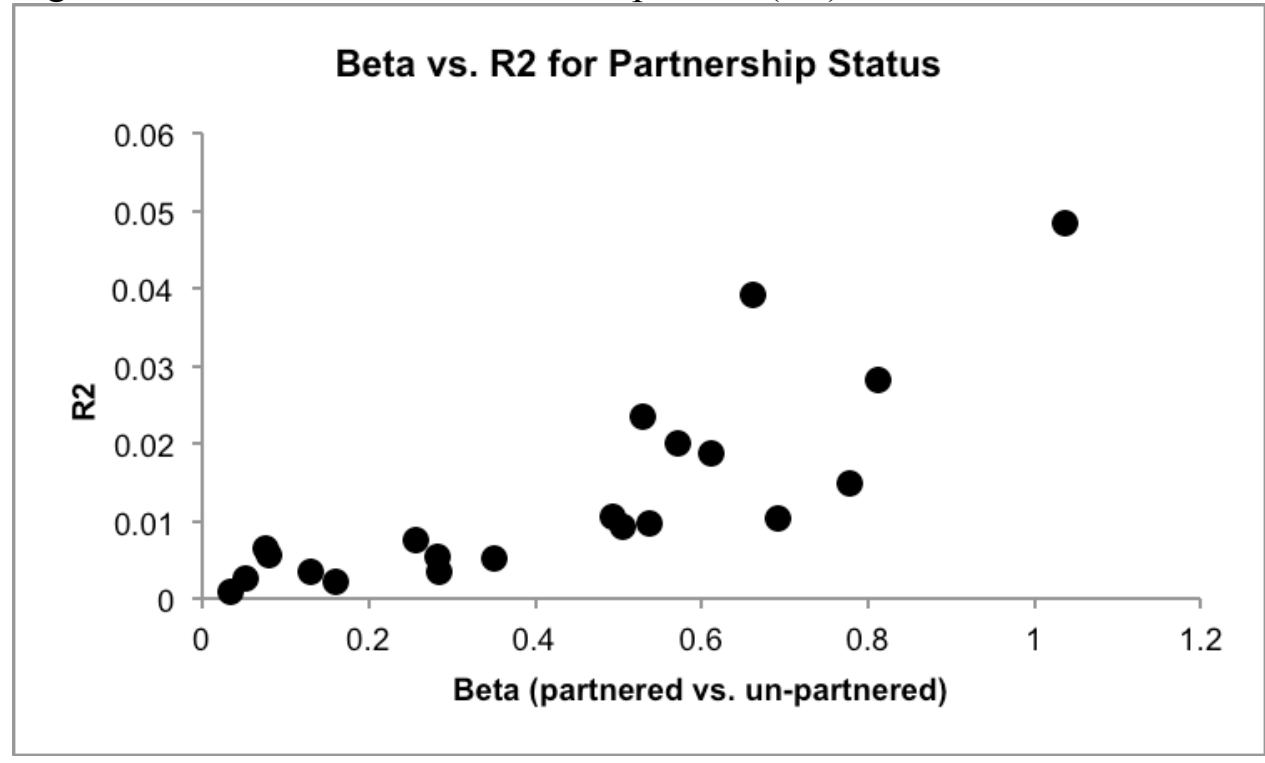

Figure A8. Measures of Variation Explained (R2) and Percent Partnered

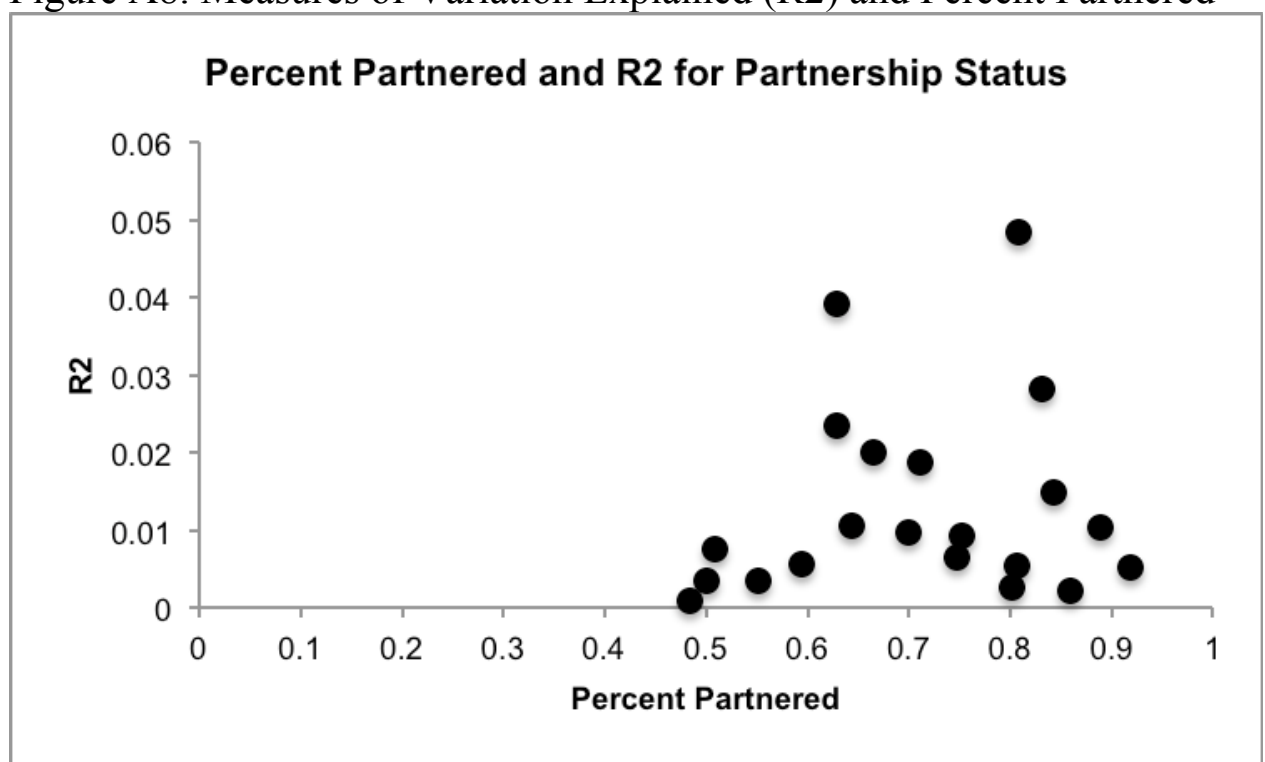


Table A1. Measures of $\mathrm{R}^{2}$, variation, and beta by region and age group

\begin{tabular}{|c|c|c|c|c|c|c|c|c|c|}
\hline Region & $\begin{array}{l}\text { Age } \\
\text { Group }\end{array}$ & $\begin{array}{l}\text { Health } \\
\text { (b) }\end{array}$ & $\begin{array}{l}\text { Income } \\
\text { (b) }\end{array}$ & $\begin{array}{l}\text { Partnered } \\
\text { (b) }\end{array}$ & Health $R^{2}$ & Income $R^{2}$ & Family $R^{2}$ & $\begin{array}{l}\text { \% Poor } \\
\text { Health }\end{array}$ & \% Partnered \\
\hline W. Europe & $20-34$ & 0.6665 & 0.0842 & 0.5303 & 0.0906 & 0.0128 & 0.0235 & 0.1876 & 0.6295 \\
\hline E. Europe & $20-34$ & 0.7325 & 0.2200 & 0.0818 & 0.0620 & 0.0430 & 0.0057 & 0.3343 & 0.5952 \\
\hline Anglophone & $20-34$ & 0.7362 & 0.1280 & 0.6623 & 0.0942 & 0.0325 & 0.0392 & 0.1151 & 0.6295 \\
\hline $\begin{array}{l}\text { Middle East/ } \\
\text { N. Africa }\end{array}$ & $20-34$ & 0.7481 & 0.2725 & 0.2861 & 0.0519 & 0.0499 & 0.0035 & 0.2089 & 0.5015 \\
\hline SSA & $20-34$ & 0.8694 & 0.3349 & 0.0341 & 0.0837 & 0.0840 & 0.0008 & 0.2927 & 0.4838 \\
\hline Latin Am. & $20-34$ & 0.6537 & 0.1550 & 0.2581 & 0.0486 & 0.0244 & 0.0075 & 0.2436 & 0.5089 \\
\hline Asia & $20-34$ & 0.5733 & 0.2751 & 0.1319 & 0.0395 & 0.0660 & 0.0034 & 0.2419 & 0.5524 \\
\hline W. Europe & $35-49$ & 0.6913 & 0.1411 & 0.8114 & 0.0995 & 0.0326 & 0.0282 & 0.2623 & 0.8318 \\
\hline E. Europe & $35-49$ & 0.7839 & 0.2505 & 0.7789 & 0.0753 & 0.0539 & 0.0148 & 0.5063 & 0.8431 \\
\hline Anglophone & $35-49$ & 0.6768 & 0.1251 & 1.0361 & 0.0854 & 0.0281 & 0.0484 & 0.1584 & 0.8088 \\
\hline $\begin{array}{l}\text { Middle East/ } \\
\text { N. Africa }\end{array}$ & $35-49$ & 0.7616 & 0.2956 & 0.6914 & 0.0602 & 0.0615 & 0.0103 & 0.2860 & 0.8883 \\
\hline SSA & $35-49$ & 0.9287 & 0.3684 & 0.2839 & 0.0942 & 0.1020 & 0.0054 & 0.3307 & 0.8069 \\
\hline Latin Am. & $35-49$ & 0.6885 & 0.1604 & 0.5060 & 0.0563 & 0.0270 & 0.0092 & 0.3190 & 0.7533 \\
\hline Asia & $35-49$ & 0.6556 & 0.3026 & 0.3509 & 0.0572 & 0.0858 & 0.0052 & 0.3320 & 0.9186 \\
\hline W. Europe & $50+$ & 0.7403 & 0.1128 & 0.6119 & 0.1178 & 0.0188 & 0.0187 & 0.4799 & 0.7116 \\
\hline E. Europe & $50+$ & 0.8447 & 0.2554 & 0.5371 & 0.0888 & 0.0469 & 0.0097 & 0.7253 & 0.6997 \\
\hline Anglophone & $50+$ & 0.5860 & 0.0789 & 0.5712 & 0.0862 & 0.0120 & 0.0200 & 0.3424 & 0.6647 \\
\hline $\begin{array}{l}\text { Middle East/ } \\
\text { N. Africa }\end{array}$ & $50+$ & 0.6050 & 0.2121 & 0.0534 & 0.0462 & 0.0309 & 0.0026 & 0.4966 & 0.8018 \\
\hline SSA & $50+$ & 0.9492 & 0.4420 & 0.0765 & 0.1058 & 0.1357 & 0.0065 & 0.4658 & 0.7481 \\
\hline Latin Am. & $50+$ & 0.5885 & 0.0902 & 0.4935 & 0.0456 & 0.0075 & 0.0106 & 0.4702 & 0.6443 \\
\hline Asia & $50+$ & 0.7179 & 0.2627 & 0.1611 & 0.0776 & 0.0681 & 0.0021 & 0.4638 & 0.8590 \\
\hline
\end{tabular}

